\title{
Aulas compartilhadas na formação de licenciandos em matemática
}

\author{
Eduardo Sarquis Soares
}

Doutorando em Educação pela Faculdade de Educação da Universidade Federal de Minas Gerais

\author{
Maria Inês Mafra Goulart \\ Universidade Federal de Minas Gerais, Faculdade de Educação
}

\section{Introdução}

Este artigo tem como propósito refletir sobre a formação inicial de estudantes da licenciatura em matemática da Universidade Federal de Minas Gerais (UFMG), a partir de dados coletados nas aulas de prática de ensino na Faculdade de Educação (FAE). A reflexão aqui apresentada insere-se em um programa de pesquisa mais amplo, cujo foco recai sobre a formação inicial e em serviço de professores. A compreensão de como se dá a tomada de consciência da prática docente e das diversas estratégias criadas pelos professores para a expansão das alternativas de ação desses profissionais é uma das preocupações do programa de pesquisa em questão.

Neste artigo, vamos nos limitar a um estudo sobre uma produção coletiva de conhecimento, a partir de um episódio ocorrido na disciplina prática de ensino. Os sujeitos envolvidos no processo são quatro licenciados do curso de licenciatura em matemática da UFMG, o professor da disciplina (Eduardo, primeiro autor), a professora de matemática, Marina, e alunos da sétima série do ensino fundamental do Centro Pedagógico da UFMG.

Durante a realização do estágio regulamentar no Centro Pedagógico, Eduardo apresentou uma proposta inovadora àqueles quatro licenciandos. Eles foram desafiados a não apenas observar algumas aulas na turma em que estavam fazendo estágio, mas também a compartilhar aulas com a professora de sala e o professor daquela disciplina. Essas aulas seriam gravadas em vídeo para posterior análise. Essa forma de trabalhar a formação inicial vem sendo denominada, na literatura inglesa, coteaching, ou seja, professores compartilham aulas e, em seguida, refletem e analisam o que ocorreu. Essa é uma forma de ampliar a compreensão e a aprendizagem de todos os envolvidos no processo por meio do exercício conjunto da prática docente.

De maneira mais convencional, nas aulas de prática de ensino de matemática tem sido desenvolvido um padrão que consiste em designar os alunos para estágios em escolas da comunidade. Nesses estágios, participam de atividades promovidas pelos professo- 
res, às vezes assumem algumas aulas e depois fazem, geralmente nas faculdades de educação, uma reflexão do que vivenciaram no processo. Esse modelo sofre algumas modificações, mas a estrutura é basicamente semelhante: alterna-se a prática do licenciando com discussões coordenadas pelo professor da disciplina, que fornece o subsídio teórico para a reflexão. Esse modelo tem sido adotado não somente no Brasil, mas também em outros países, conforme atestam Roth e Tobin (2002b). No entanto, a FAE da UFMG já vinha há algum tempo apresentando inovações na prática de ensino, o que gerou um clima propício à experimentação de novas estratégias de formação inicial.

Neste artigo, relatamos uma experiência que utilizou abordagem diferenciada para problematizar as formas mais convencionais de formação inicial. Verificamos que a adoção do coteaching como estratégia de formação permitiu um confronto direto com os pressupostos e conceitos elaborados pelos licenciandos, possibilitando a construção de um conhecimento que só se realiza na prática. A reflexão posterior empreendida pelos licenciandos e professores, mediada pelo vídeo, permitiu um avanço na compreensão do que ocorreu, contribuindo para que todos ampliassem suas percepções acerca do exercício da profissão. Nessa perspectiva, a aprendizagem é localizada em um processo de co-participação social, é produzida em contextos de ação e não apenas em estruturas mentais e lingüísticas (Roth, 1995). Em nossa experiência, a análise dos registros coletados evidenciou processos de aprendizagem significativos não programados e irreversíveis, no sentido de que não há como reproduzi-los em outro momento ou em outro contexto. Acreditamos que esses processos são engendrados por influências de um número incontável de fatores. Em razão dessas características relacionadas à imprevisibilidade de resultados, a sala de aula configura-se como um ambiente afastado das condições de equilíbrio, da forma descrita por Prigogine (1996).

Para construir nossa argumentação, iremos inicialmente descrever o contexto em que essa prática foi realizada. Em seguida, apresentaremos o conceito de coteaching baseado nos trabalhos de pesquisado- res da atualidade (Roth, 2002; Roth \& Tobin, 2002a, 2004; Tobin, Roth \& Zimmermann, 2001; Gallo-Fox et al., 2006) em contraposição a outros processos de formação contemplados na literatura para finalmente apresentar a análise que fizemos da experiência que desenvolvemos.

\section{O contexto e os primeiros movimentos da experiência}

Os alunos de licenciatura que cursam a prática de ensino de matemática na FAE-UFMG obrigatoriamente fazem estágios em escolas de ensino fundamental ou de ensino médio. No primeiro semestre de 2006, alguns alunos foram designados para estagiar no Centro Pedagógico, sob a coordenação de Marina, que lecionava para o segundo ano do terceiro ciclo, o que corresponde à sétima série do ensino fundamental. $\mathrm{O} \mathrm{CP}$, como é chamado, é uma escola pública federal que tem como objetivo ministrar ensino em que a investigação é considerada base para a produção de conhecimento. Esse espaço propício para experimentações pedagógicas que subsidiem avanços e reflexões sobre a prática educativa constitui um campo de estágio para alunos das licenciaturas ministradas na UFMG. Atualmente, as crianças são admitidas no primeiro ano do ensino fundamental por meio de sorteio, procurando assim evitar a prática de concursos que acabam por favorecer indivíduos oriundos de camadas socialmente privilegiadas.

Durante certo período, aqueles quatro licenciandos seguiram as aulas de Marina assumindo o acompanhamento de alunos, especialmente alguns com maior dificuldade. Depois de estarem mais familiarizados com o ambiente, aceitaram o desafio de lecionar duas aulas de geometria.

Normalmente, Marina participaria dessas aulas, podendo interferir quando julgasse necessário; posteriormente, avaliaria os resultados com os licenciandos a partir do que eles haviam registrado acerca dos acontecimentos. Entretanto, a programação ficou enriquecida com a nova proposta e com a entrada em cena dos recursos de registro em vídeo. De maneira simplificada, tal estratégia consistiu em: 
- promover aulas em que professores iniciantes e veteranos compartilham a condução dos trabalhos;

- registrar essas aulas em vídeo; e

- avaliar os acontecimentos coletivamente, a partir dos registros gravados.

Convencidos da possibilidade de empreender a experiência, os professores veteranos explicaram a estratégia que desejavam adotar aos licenciandos, que concordaram em participar da proposta. Na programação das aulas, estes últimos foram assistidos pelos professores veteranos.

Para a primeira aula, os licenciandos programaram algumas atividades e especialmente algumas experiências em que os alunos, organizados em grupos, fariam medidas dos comprimentos da circunferência e do diâmetro e calculariam o valor da divisão da primeira medida pela segunda, o que teoricamente forneceria um valor próximo do número pi $(\pi)$. Em seguida, seriam oferecidas explicações sobre esse número, com destaque para o fato de tratar-se de um número irracional. Para o segundo encontro, os licenciandos programaram aulas expositivas que seriam conduzidas por um ou dois professores com o objetivo de trabalhar conceitos teóricos como: elementos da circunferência (raio, diâmetro, corda), posições relativas de uma reta e uma circunferência e posições relativas de duas circunferências.

Durante as aulas, os quatro licenciandos, a professora da turma e Eduardo compartilharam a posição de professor. Cada licenciando assumia a posição central conforme haviam combinado previamente, mas qualquer colega que estava aguardando a vez ou qualquer um dos professores veteranos poderia assumir essa posição perante a turma da sétima série quando avaliasse que isso fosse pertinente.

Todos estavam cientes, de antemão, de que haveria assimetrias no grupo dos professores, dadas as diferentes condições de participação. Assim sendo, o peso da intervenção de cada um seria diferenciado. O que observamos na literatura é que nem sempre o coteaching é exercido por professores cujo grau de conhecimento e habilidades é tão discrepante. Essa assimetria, no entanto, não só era inevitável como constituía o cerne do processo de formação. Era ela que criava o ambiente propício para a aprendizagem dos licenciandos. As contradições e os conflitos advindos da experiência seriam o motor do desenvolvimento de todo o grupo. Desentendimentos graves entre os professores poderiam também acontecer, conforme se pode verificar na literatura acadêmica, e o grupo estava ciente disso. Entretanto, nenhum participante colocou obstáculo e a experiência foi realizada em relativa harmonia.

Alguns dias depois, licenciandos e professores reuniram-se para discutir o que ocorrera, dispondo das filmagens das aulas. Nesse encontro, o grupo elegeu um episódio para analisar com mais profundidade e discutiu significados que cada participante atribuiu a tal episódio. Depois disso, o grupo convidou alguns alunos para representar a turma em outra reunião e participar da avaliação das aulas em geral e do episódio em particular. Posteriormente esses eventos foram analisados por um grupo de estudo e pesquisa do qual fazem parte os autores deste artigo.

Considerando os objetivos deste texto, vamos oferecer uma descrição panorâmica da segunda aula e iremos nos deter especialmente em um episódio que traz elementos valiosos da importância da estratégia utilizada para avançar a discussão sobre a formação inicial. Todavia, antes de prosseguir com a narrativa, iremos desenvolver o conceito de coteaching, baseado em Roth e Tobin (2002a, 2004), apresentando aspectos dessa abordagem para a formação inicial de professores por meio de uma dupla estratégia, ou seja, a ação conjunta entre veteranos e iniciantes e a reflexão posterior sobre o ocorrido. Argumentamos que essa maneira de abordar a formação traz novos elementos para discussão, uma vez que acreditamos que muito do que o professor aprende sobre sua profissão acontece enquanto age e um dos desafios que temos de enfrentar consiste em verificar o que se aprende nesse movimento. 


\section{Coteaching: uma abordagem fecunda na formação de professores}

Dentre as pesquisas sobre a formação do professor em uma perspectiva dialética, destacamos a abordagem que enfoca o desenvolvimento dos professores na prática e a construção de ambientes educacionais ricos em possibilidades de aprendizagem. Na revisão feita por Soares (2004) sobre as pesquisas desenvolvidas por Roth (2002), pode-se perceber o esforço do pesquisador para revelar as condições concretas que envolvem o trabalho do professor, utilizando-se de uma abordagem centrada na relação dialética entre práxis e praxeologia. Esta emerge do diálogo sobre os eventos e ocorre em tempo cronológico. Produz, dessa forma, uma teoria que nunca se completa, porque cada elemento da realidade pode gerar outros elementos para a compreensão dos eventos. Segundo Roth (2002), as pesquisas tradicionais sobre a formação do professor exploram essa única dimensão temporal: o tempo cronológico. Com o objetivo de ampliar essa visão, esse autor explora a relação dialética entre duas dimensões temporais: o tempo fenomenológico e o tempo cronológico.

Por tempo fenomenológico entende-se aquele tempo irreversível, da experiência vivida, do aqui e agora. É o tempo predominante na sala de aula, onde tudo ocorre de forma contínua, onde as decisões são tomadas com um tempo mínimo para reflexão. Nesse processo, um conhecimento específico é construído. Essas formas de conhecimento produzidas na ação resultam na produção de ferramentas que auxiliam os professores em seu fazer cotidiano e estão disponíveis para aqueles que se engajam em uma atividade real.

O tempo cronológico, por sua vez, é aquele em que a realidade é representada, ou, melhor dizendo, reapresentada na forma de uma interpretação do que ocorreu no passado (Goulart, 2005). Normalmente as teorias baseadas apenas no tempo cronológico tendem a considerar os eventos como reversíveis. Isso significa que, ao produzirem generalizações amplas, elas tomam como possível a reprodução de determinados fenômenos em uma realidade diferente daquela em que ocorreram primordialmente. Nessas abordagens, corre-se o risco de desconsiderar diferenças significativas nas configurações situacionais.

Essas dimensões temporais não existem isoladamente, mas a postulação de sua existência permite que nos expressemos melhor sobre experiências temporais diferenciadas. Por exemplo, quando caminhamos por uma rua movimentada no centro de uma cidade, podemos fazê-lo privilegiando a dimensão fenomenológica, porque é importante prestar atenção aos locais por nos quais passamos e, conforme a região, até mesmo aos pontos nos quais devemos pisar. Em contrapartida, se andamos por um lugar conhecido (que exige pouca atenção às passadas) enquanto refletimos sobre algo que está na memória, privilegiamos a dimensão cronológica sem abandonar a dimensão fenomenológica. $\mathrm{Na}$ prática pedagógica, enquanto planejamos uma aula, focamos nossa atenção na dimensão cronológica, porque podemos refletir sobre experiências passadas e projetar acontecimentos no futuro; em contraste, enquanto lecionamos, estamos imersos na dimensão fenomenológica.

Entretanto, defendemos que as formas de conhecimento adquiridas na práxis não podem ser repassadas por prescrições, porque se desenvolvem enquanto os professores enfrentam as condições reais de trabalho. Esses conhecimentos distinguem os professores novatos dos experientes.

Apresentando vasto material empírico em que analisa a dialética tempo fenomenológico/tempo cronológico, Roth propõe que, para seu desenvolvimento profissional, os professores se beneficiem da ajuda dos pares. Isso pode ser feito quando professores atuam coletivamente em uma mesma sala de aula dedicando depois algum tempo para reflexão, ou seja, trabalham concomitantemente na dimensão da práxis e da praxeologia.

Essa perspectiva é largamente explorada por pesquisadores atuais (Roth \& Tobin, 2002b, 2004; Tobin, Roth \& Zimmermann, 2001; Roth et al., 2004). A prática de compartilhamento da sala de aula com posterior reflexão sobre os acontecimentos é estudada por esses autores, que a denominam coteaching e cogenerative 
dialoguing. Esse é um processo no qual dois ou mais professores assumem a responsabilidade de planejar, executar e discutir os acontecimentos vivenciados.

Segundo esses pesquisadores, coteaching tem como fundamento uma epistemologia fenomenológica, cujo foco se baseia no fato de os professores estarem juntos aprendendo sobre a prática docente. A experiência de estar na sala de aula e perceber diretamente o ambiente não pode ser substituída pelo discurso sobre o que ocorre ou ocorreu naquele ambiente, porque são diferentes as dimensões temporais envolvidas no discurso e na prática. Daí a importância de assumir a participação na prática profissional como um elemento imprescindível para a formação do licenciando.

O conceito de habitus, como foi desenvolvido por Bourdieu (1983), acrescenta elementos à nossa argumentação. Seguindo interpretações de Sewell (1992) e de Roth (2002), tomaremos habitus como uma matriz de percepções que os indivíduos constroem à medida que ficam expostos a um mesmo ambiente por tempo prolongado. Professores iniciantes atuam com as percepções que desenvolveram como alunos acerca de ser professor, o que significa que ainda não têm construído o habitus de professor. O desenvolvimento de habitus processa-se de maneira dinâmica no tempo fenomenológico. Essa matriz de percepções vai evoluindo quando o indivíduo, geralmente de maneira inconsciente, se vai capacitando a antecipar o resultado de suas ações em um futuro imediato. Somente a confrontação com a realidade no exercício da profissão permite que o habitus de um professor se desenvolva. A título de exemplo, imaginemos um professor iniciante defrontando-se com um ato de indisciplina de um aluno ao qual tem de reagir imediatamente. Esse professor tenderá a agir conforme uma imagem que tem em mente, mas que ainda não foi testada na prática. Ato contínuo, sua ação provocará um resultado satisfatório ou não para ele; esse resultado ficará inscrito em sua memória e influenciará suas decisões futuras. O conjunto de tais experiências vai engendrando uma matriz de percepções que ajuda o profissional a tomar determinadas atitudes naquele ambiente de trabalho. À medida que esse conjunto de experiências se vai alargando, o habitus do professor vai fortalecendo-se. Exatamente porque se constrói na dimensão fenomenológica do tempo, e de maneira um tanto inconsciente, o habitus resiste tenazmente a mudanças. Isso nos ajuda a compreender porque é muito mais fácil evoluir no discurso do que nas ações. Também reforça a proposta de procurar melhorar nossa compreensão acerca da prática profissional pelo compartilhamento de aulas entre profissionais. Sabemos, contudo, que a experiência envolve riscos, especialmente se os profissionais que dela participam não desenvolvem um relacionamento baseado na confiança mútua.

O artigo de Gallo-Fox et al. (2006), por exemplo, explora questões éticas e dificuldades decorrentes de uma proposta de coteaching que não obteve a adesão sincera de todos os envolvidos. Acompanhando o que está relatado ali, podemos verificar que a adesão e o esforço do grupo para que o trabalho aconteça em um clima amistoso formam uma base que promove a necessária sustentação ao compartilhamento de aulas. Felizmente, na nossa experiência não emergiram conflitos dessa natureza. Pelo contrário, nossa percepção é de que, mesmo enfrentando conflitos, o grupo trabalhou de forma bastante coerente com a proposta, e por isso não vamos nos alongar na discussão desses problemas.

Há trabalhos voltados para o aperfeiçoamento de professores que procuram evidenciar o que chamam de saberes experienciais desses profissionais. O desenvolvimento de narrativas sobre práticas vividas constituiria uma forma de acessar esses saberes experienciais e desenvolver uma reflexão sobre eles. É o caso, por exemplo, do processo registrado por Fiorentini, Nacarato e Pinto (1999). Uma das questões que esses autores procuram enfrentar diz respeito à constatação de que a prática dos professores muda muito mais lentamente que o discurso teórico sobre educação. Somos capazes de perceber mais rapidamente o que tomaríamos como um ideal a ser seguido do que realmente mudar a prática na direção pretendida. Para Fiorentini, Nacarato e Pinto, assim como para Tardif 
(2002), uma chave para compreender essa discrepância encontra-se no fato de que muitas teorias pedagógicas não levam em conta os saberes que os professores desenvolvem na prática e que deveriam ser considerados relevantes pelas teorias que pretendem alcançar alto grau de generalização. Reconhecemos a importância desses trabalhos e também pretendemos voltar nossos esforços para melhor compreender a prática docente, embora nosso ponto de vista seja diferente. As narrativas de que falam esses autores ocorrem na dimensão cronológica do tempo. No nosso caso, procuramos acessar o que ocorre na dimensão fenomenológica. A escolha por essa abordagem teórico-metodológica decorre do pressuposto de que o professor aprende muito sobre seu ofício enquanto age. Nosso desafio, enquanto pesquisadores, passa a ser então verificar o que se aprende nesse movimento.

No entanto, capturar movimento é uma tarefa bastante complexa. Até porque muitos elementos circunstanciais interferem no trabalho do professor. Essa idéia remete-nos ao conceito de sistemas longe do equilíbrio, desenvolvido por Prigogine (1996). Segundo esse autor, os acontecimentos que ocorrem em ambientes afastados do equilíbrio são influenciados por um número muito grande de fatores; pequenas variações em um deles podem modificar substancialmente o curso dos acontecimentos em todo o ambiente. Percebemos a sala de aula como um desses ambientes. Há fatores decorrentes de condições sociais mais amplas que tendem a variar mais lentamente, como a maneira de viver das classes sociais em que se inserem as famílias que compõem a comunidade escolar. Outros fatores variam mais rapidamente. $\mathrm{O}$ encontro entre professor e alunos é influenciado, por exemplo, pelo estado emocional dos sujeitos envolvidos, e esse estado emocional depende das circunstâncias que interferem no dia-a-dia de cada um. Como nossa proposta pretende buscar a compreensão da aprendizagem do grupo de licenciandos e professores a partir de uma prática compartilhada, estamos sujeitos a todas essas variações. Contudo, estamos convencidos de que há elementos de nossa experiência que serão considerados familiares para outros profissionais da educação, o que nos permitiria apostar na possibilidade de certo grau de generalização das aprendizagens colhidas. É preciso reconhecer também que trabalhamos em um ambiente propício a inovações, o que pode ser visto como uma exceção, tendo em vista que os professores muitas vezes atuam em escolas com regras rígidas. Porém, acreditamos na possibilidade de cada sujeito favorecer mudanças; acreditamos que estas, mesmo pequenas, podem ser significativas, como argumentaremos em seguida.

Uma maneira de compreender as estruturas sociais e o impacto provocado nelas pelas mudanças ocasionadas pelo poder de agir dos atores sociais foi desenvolvida por Sewell (1992). Segundo esse autor, todos temos, em algum nível, a capacidade de transformar as estruturas com as quais lidamos. As estruturas vão-se transformando, mesmo que lentamente, a partir de ações inovadoras dos sujeitos. A ação transformadora resulta da tensão entre as condições dadas e o desejo de mudá-las. Essa ação transformadora, ou o poder que os atores sociais têm de agir e de mudar situações dadas, é chamada agency, por esse e outros autores, como Emirbayer e Mische (1998). Sendo assim, os sujeitos não só reagem às estruturas que os constrangem, mas são dotados do poder de mudar essas condições.

Em nossa investigação, trabalhamos a análise levando em conta a assimetria entre os dois grupos de professores. Isso significa dizer que a capacidade de produzir mudanças, ou, como assinala Sewell (1992), de usar a agency com o propósito de produzir mudanças no ambiente, fica também diferenciada. Um professor novato tende a sentir desconforto porque desconhece o ambiente ou desconhece a posição que passa a ocupar na sala de aula quando muda da condição de aluno para a de professor, ou seja, ainda não desenvolveu um habitus de profissional. Podemos dizer, como Roth (2002), que o iniciante tem pequeno espaço de manobra, porque não tem ou tem poucas experiências de confronto com sua imagem sobre como é ser professor. Quanto mais exposto ao ambiente, mais o indivíduo tende a aumentar o leque de possibilidades de ação diante das circunstâncias, ou seja, o 
professor pode ir ampliando seu espaço de manobra no exercício da profissão. No entanto, reconhecemos que essa situação também pode ser problematizada. Um iniciante, por ter pouco comprometimento com a estrutura enrijecida da escola, pode promover maiores mudanças que os veteranos.

\section{Ampliando espaços de manobra}

A segunda aula compartilhada, que ocorreu uma semana após a primeira, começou com uma intervenção de Marina conclamando a turma a organizar-se e relembrando rapidamente o que havia acontecido na semana anterior. Ela destacou o que era de interesse para o planejamento dos licenciandos, qual seja o fato de que as divisões efetuadas pelos alunos, medida do comprimento da circunferência pela do diâmetro, resultaram em "números muito parecidos, apesar de as circunferências serem de tamanhos diferentes". Com essa fala, a professora estava sugerindo que os alunos deveriam considerar que os experimentos indicavam um resultado comum a todos eles.

Pela programação, a aula iniciaria sob a coordenação de dois licenciandos, Kátia e Gil. ${ }^{1}$ Mas, antes de seu início, um terceiro, Ângelo, pediu para ocupar a posição central para completar uma discussão que ficara pendente na primeira aula. A quarta licencianda, Kenia, permanecia no fundo da sala. O grupo de professores assentiu e, assim, ele iniciou com uma explicação sobre o número $p i$, que resultaria da divisão da medida de qualquer circunferência pela medida do diâmetro correspondente. Os alunos haviam feito essas medidas e a divisão correspondente na primeira aula. Ao dizer que os resultados obtidos pelos alunos se aproximavam do valor de $p i$, Ângelo estava forçando uma avaliação desses resultados que somente poderia ser considerada razoável por alguém que soubesse de antemão o que teoricamente deveria acontecer. De fato, os resultados obtidos experimentalmente pelos alunos

${ }^{1}$ Os nomes dos participantes foram alterados para proteger sua identidade. Os professores de prática de ensino e matemática mantiveram sua denominação. diferiam consideravelmente uns dos outros. Contudo, Ângelo não deu destaque às diferenças, mas assumiu sua condição de autoridade para guiar o olhar dos alunos para uma suposta convergência dos resultados. $\mathrm{Na}$ nossa interpretação, Ângelo estava, assim, imaginando que seu discurso seria suficiente para fazer com que os alunos desconsiderassem o que obtiveram empiricamente. Sua fala durou aproximadamente nove minutos, sem que houvesse qualquer participação dos alunos além de uma ligeira observação de um aluno, que foi incorporada rapidamente ao discurso do professor.

Kátia assumiu então a posição central, colocandose de frente para a turma. Ela deveria explicar as posições relativas da reta e da circunferência, mas decidiu dedicar um tempo para verificar se os alunos tinham domínio dos conceitos de diâmetro, raio e corda. Lembrou aos alunos que, na aula anterior, Kenia havia falado sobre os elementos da circunferência. Fez um desenho (Figura 1) e os desafiou a identificar quatro cordas, com o intuito de verificar se eles sabiam o que é uma corda.

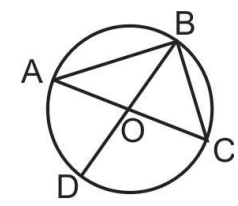

Figura 1

Uma aluna arriscou dizer que uma corda seria OC (O é o ponto do centro da circunferência; portanto, OC seria um raio e não uma corda). Kátia redargüiu perguntando o que é uma corda e dirigindo a pergunta aos outros alunos, para que identificassem as cordas. Eles foram respondendo corretamente $(\mathrm{COA}, \mathrm{AB}$, $\mathrm{AC})$ e ela retornou à aluna que havia indicado o ponto O para dizer que a definição de corda mostrava que segmentos como OA, OB ou outro qualquer com o extremo em $\mathrm{O}$ não poderiam ser cordas. Eis um extrato do diálogo entre Kátia e os alunos. ${ }^{2}$

\footnotetext{
${ }^{2}$ Usamos as seguintes convenções para as transcrições: - palavras que foram omitidas na linguagem oral foram trans-
} critas entre parênteses para auxiliar a compreensão ( ); - ações relevantes são transcritas dentro de duplo parênteses (( )); 
Episódio 1

1. Kátia: Cordas... Vocês conseguem identificar nesta figura? Lembrando o que é uma corda... Se alguém souber, pode falar.

2. A1: Eu acho que o $\mathrm{O}$ com o $\mathrm{C}$.

3. Kátia: O O com o C? É uma corda? O que é uma corda?

4. A2: COA.

5. A3: $\mathrm{AC}, \mathrm{AB} \ldots$

6. Kátia: COA. Então, sendo COA, o que uma corda faz então?

7. A1: Liga...

8. Kátia: Isso. Ela liga dois pontos da circunferência, não é? ((Voltando-se para a aluna)). Por isso que o OC não é uma corda, porque ele está ligando o centro a (um ponto da) circunferência. Então, uma corda seria CA...

((Escreve as duas letras no quadro)). Qual mais?

À primeira vista, poderíamos imaginar que Kátia tinha um conteúdo em mente que deveria ser abordado e permitia que os alunos se manifestassem desde que em colaboração com o encaminhamento do assunto. Desse ponto de vista, a professora não teria como objetivo tratar as concepções dos alunos, mas fazê-los compreender os conceitos que pretenderia ensinar ou, no caso presente, rememorar. Contudo, há nuanças que deveriam ser levadas em conta. Em primeiro lugar, Kátia não desconsiderou simplesmente o que a aluna havia dito. Prova disso é que retornou a atenção à aluna na esperança de que ela tivesse compreendido seu próprio engano em vista das colocações dos colegas e da definição sugerida pela própria professora (turno ${ }^{3} 8$ ). Em segundo lugar, Kátia manteve-se fiel a um princípio pactuado entre os quatro licenciados. Durante o planejamento, eles haviam combinado não

- corte nas falas são transcritos com três pontos entre parênteses $[\ldots]$;

- pontuações são usadas para indicar características da produção discursiva e não de unidades gramaticais...?

${ }^{3} \mathrm{O}$ termo turno está indicando o enunciado de cada participante. A numeração utilizada visa facilitar o acesso a um determinado enunciado indicado no texto. entregar respostas prontas aos alunos, mas fazê-los "construir" os conceitos, devolvendo-lhes as dúvidas com novas perguntas.

Colocamos o verbo construir entre aspas porque percebemos que, inerente à combinação dos licenciandos, estava presente a idéia de que os alunos constroem conhecimentos quando vão procurando responder às perguntas do professor até chegar à formulação de uma resposta que reproduz um conceito que o professor pretende ensinar. Nesse diálogo, verificamos, nos turnos 4 e 5, que os alunos apresentaram as respostas desejadas pela professora. Com isso, ela apressou-se em definir o que seria uma corda (turno 8) e indicou à aluna o que ela deveria compreender, seguindo adiante.

A professora não quis verificar com mais detalhes o nível de compreensão da aluna, talvez porque julgasse que ela teria compreendido seu engano, talvez por não dispor de tempo suficiente para proceder a tal verificação. De todo jeito, o desenrolar dos acontecimentos, até esse momento, parecia reforçar as convicções dos licenciandos acerca de como deve atuar um professor e de como os alunos aprendem. Até então, ainda não haviam enfrentado alguma contrariedade. Todavia, a fidelidade ao princípio combinado pelos licenciandos fez com que, pouco depois, Kátia se visse diante de um dilema.

Kátia prosseguiu fazendo com que os alunos apontassem os pontos que definiam todas as cordas, os raios e os diâmetros do desenho, destacando as definições, enquanto alguns respondiam corretamente às perguntas que ela lançava. Na sequiência, Marina aproveitou o momento em que Kátia fazia anotações no quadro e interveio propondo algumas questões para a turma: "Vocês conseguem achar alguma corda menor que o diâmetro?". Alguns responderam afirmativamente e ela voltou a perguntar: "E maior?". Depois de uma tímida negativa, perguntou novamente: "Têm certeza de que não há nenhuma corda maior?". Pausa, os alunos calados... Kátia retomou a fala: "Uma pergunta interessante... ((dirigindo-se à professora de matemática)). Vamos pensar nisso agora ou vamos deixar para depois?". 
Por meio de sua intervenção, Marina propunha uma maneira diferente de conduzir a aula, tentando colocar para os alunos uma questão mais aberta, que não poderia ser respondida imediatamente, mas exigia certo exame das condições dadas e argumentação na resposta. Assim, Marina lançava mão do espaço de manobra mais desenvolvido para permitir que as manifestações dos alunos fossem além de simplesmente fornecer respostas tentando sintonizar-se com o que seria considerado correto por Kátia. Com a pergunta dirigida a Marina, Kátia estava expressando o reconhecimento de uma possibilidade aberta, mas também certa preocupação com o tempo, uma vez que ainda não abordara a maior parte do conteúdo que lhe cabia tratar. Vale notar que Kátia mantinha consigo uma folha com o planejamento dos passos que deveria seguir durante a aula. Marina compreendeu a ponderação e deixou a aula prosseguir.

Apesar dessa intervenção, Kátia manteve o mesmo tipo de interatividade com os alunos, talvez porque não se via com flexibilidade suficiente para mudar a forma de conduzir o diálogo. De fato, tinha poucas alternativas de ação à sua disposição, o que é o mesmo que dizer que tinha ainda um pequeno espaço de manobra, característica própria de todo iniciante.

\section{Os acontecimentos estavam sob controle até que...}

No movimento seguinte, Kátia pretendia fazer com que os alunos enunciassem as posições relativas entre uma reta e uma circunferência. Teoricamente, as posições entre uma reta e uma circunferência situadas em um mesmo plano são três: a reta pode não encontrar a circunferência, pode cortar a circunferência em 2 pontos e pode tocar a circunferência em um ponto apenas, como sugere a Figura 2.

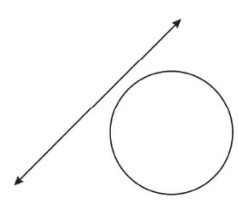

Reta externa à circunferência

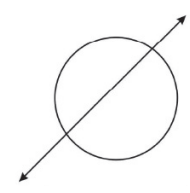

Reta secante à circunferência

Figura 2

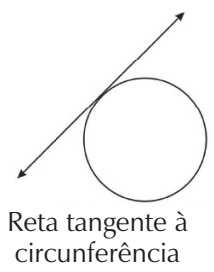

circunferência
O desafio de Kátia consistia em fazer com que os alunos percebessem que essas são as únicas posições possíveis, sem que precisasse transmitir o que já está estabelecido na matemática teórica. Para isso, ela deveria colocar uma questão adequada para fazê-los pensar. A dificuldade consistia em formular uma boa questão que não contivesse uma das respostas possíveis na própria formulação.

Episódio 2

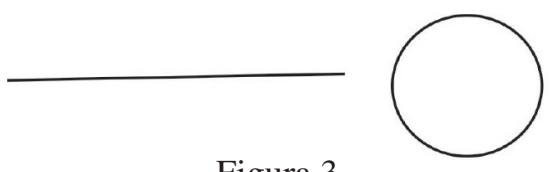

Figura 3

1. Kátia: Então, agora, eu vou dar para vocês uma reta... ((Desenha um segmento e uma circunferência-Figura 3)). Vamos supor que vocês tivessem isso nas mãos. De que maneira eu posso posicionar minha reta e minha circunferência? Vocês têm uma reta... Como se vocês pudessem pegar mesmo na reta e na circunferência. Eu quero que vocês falem para mim... ((Muda a entonação para perguntar)). De que maneira eu posso posicionar a minha reta e a minha circunferência? Quais as possíveis posições entre essas duas... Entre a reta e a circunferência que eu dei... Entenderam?

2. A1: Não.

3. Kátia: Não? ((Sorrindo e olhando para Marina)). É... Eu quero arranjar as duas... Combinar essas duas coisas juntas... Como que eu poderia colocar? ((Silêncio)).

4. Kenia ((Entrando em cena)): Por exemplo...

5. Ângelo ((Entrando em cena)): Alguém vai lá e desenha uma reta e uma circunferência, por favor. ((Neste momento, Gil aproxima-se do quadro. Apesar de não dizer nada por muito tempo, fica ao lado de Kátia)).

6. Kátia: É. Desenha uma circunferência e uma reta e... De quais maneiras eu posso desenhar?

7. Marina: A reta pode encostar na circunferência? Pode atravessar? Pode o quê? ((Silêncio)).

8. Kátia: ((Vai falando, deixa a folha de anotações sobre a mesa do professor para liberar as mãos, e vai gesticulando, mostrando a forma dos objetos que está mencionando)). Vamos supor que eu tivesse um bambolê... E um... Um cabo de vassoura, uma coisa reta.. De que maneira eu posso colocar essas duas coisas? Eu posso pegar nessas duas coisas, não posso? 
9. A1: Pode.

10. Kátia: Eu posso mexer... De que forma eu posso colocar? O cabo... A vassoura...

11. Marina: Separados... e se eu quiser juntar...

12. Kenia: Vocês vão fazer tipo uma obra de arte.

13. Kátia: É. Vocês podem fazer o que quiserem. Podem virar... A reta... Vamos pensar no cabo da vassoura. ((De novo, abre as mãos como se estivesse segurando as duas pontas de um cabo de vassoura)). Você pode levantar, pode virar, o que quiser, não é? ((Gesticulando com uma mão, como se estivesse girando o cabo de vassoura))

14. Marina: Experimentem desenhar aí no caderno de vocês...

15. Kátia: Ou aqui mesmo... ((Apontando para o quadro)).

16. Kenia: Chama alguém.

17. Gil ((Para a turma)): Quem quer vir no quadro?

18. ((Uma aluna começa a levantar-se da cadeira)). Kátia: Vem cá...

19. Kenia: Fecha o livro, se não, não tem graça, não.

20. Marina ((Falando para toda a turma)): Ah... O livro deixa na mochila.

21. Kenia: Porque, se vocês olharem no livro, não tem graça. ((Alguns alunos guardam seus livros nas mochilas)).

22. Kátia: Ah... Ninguém vai vir fazer aqui, não?

23. A2: Mas só que não dá... A reta tem que ser maior que a circunferência.

24. Kátia: Qual é o tamanho de uma reta? ((Sorri para Gil. Depois, fala para a turma)). Ela falou assim, gente... Então a minha reta tem que ser maior que a circunferência. Ela está perguntando se eu quero uma reta maior que a circunferência ou menor. Qual é o tamanho de uma reta? ((Silêncio, até que uma aluna, baixinho, diz que não tem tamanho)). Não tem tamanho, não é? A reta é infinita. Então, se eu falei que é uma reta, tem essa idéia, uma coisa infinita. O que você está perguntando seria um segmento, né? Aí, o segmento tem tamanho, ele pode ser uma coisa maior ou menor. Então eu quero uma reta e uma circunferência. Eu quero que vocês arranjem aí de que forma que essas duas coisas podem ficar. ((Vai saindo de cena, os alunos desenham, os professores conversam entre si durante um tempo de 28 segundos)).
25. Kátia: Aqui... Tem gente desenhando várias retas... Eu quero uma reta só e uma circunferência.

26. Gil: ((Depois de examinar apenas um caderno de aluno, vai ao quadro e desenha - Figura 4)). Gente, por exemplo, olha... Eu desenharia assim, ó... Uma circunferência... Depois uma reta cortando em dois pontos, por exemplo.

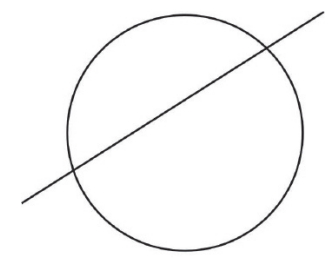

Figura 4

27. Marina: Mas será que essa é a única posição em que a gente consegue colocar a circunferência...

28. Eduardo: Mas vejam bem - o que ele falou? Ele falou que a reta dele corta a circunferência em dois pontos. Eu posso colocar essa reta de várias maneiras aqui ( (gesticulando e mostrando possibilidades de desenho de outras secantes)), mas ela vai continuar cortando a circunferência em dois pontos. Então, esse tipo de exemplo, uma reta que corta a circunferência em dois pontos, ele já deu. Agora, vocês têm que arranjar outros exemplos.

Observando esse episódio no vídeo, Kenia comentou: "Às vezes, a gente acha que o planejamento vai ser exatamente do modo que a gente acha que tem que fazer e, por seguir o planejamento, a gente pode ficar perdida ali. Por seguir o combinado, acontece isso... E a gente fica sem saber o que fazer".

O episódio mostra o esforço de Kátia para coordenar a necessidade de ser clara e a determinação de não fornecer a resposta que queria ouvir dos alunos. Essa tensão levou os licenciandos Gil, Kenia e a professora Marina a interferir, mas praticamente todas as tentativas de esclarecer a tarefa para os alunos sem quebrar o princípio combinado foram infrutíferas, ou seja, os licenciandos tiveram grande dificuldade de fazer-se entender pelos alunos.

O vídeo mostra que até o momento correspondente ao turno 15 os alunos ainda não sabiam que deveriam fazer desenhos. Na reunião de avaliação, Kátia 
comentou que, durante o planejamento, os licenciandos tentaram prever o que fariam diante de algumas dificuldades que imaginavam que os alunos iriam apresentar, mas não haviam pensado na possibilidade de os alunos não entenderem o desafio proposto. Apesar de estar incomodada com o silêncio dos alunos, Kátia sabia que "[...] o silêncio dos meninos não era só para mim". Com isso, expressou sua confiança na equipe naquele momento. De fato, a pronta intervenção dos colegas mostrou que ela não se enganara.

Na mesma reunião, Marina conscientizou-se de que sua interferência (turno 7) sugeria a resposta quase completa. Sua colocação, entretanto, não foi suficiente para que os alunos compreendessem o que estava sendo pedido a eles. $\mathrm{O}$ descompasso entre a proposta dos licenciandos e o processo de entendimento dos alunos ilustra como progride a construção do espaço de manobra do professor. Como foi observado por Kenia, esse conflito não estava previsto no planejamento dos licenciandos. Diante da incompreensão dos alunos, Kátia não tinha um arsenal de possibilidades para fazêlos compreender o que estava sendo demandado. Seus colegas tentaram ajudar, mas ninguém produziu uma solução dentro do princípio pactuado no planejamento. Gil rompeu com o combinado.

Gil definiu a saída para o problema quando resolveu desenhar no quadro a reta secante à circunferência. Kenia comentou durante a avaliação que, naquele momento, sentiu que Gil havia traído o grupo. Mas, na percepção de Gil, aquela era a única maneira de ficar claro para os alunos o que deveriam fazer. Ângelo concordou com ele argumentando que, na percepção dos professores, falharam todas as tentativas de comunicação e, portanto, a aula estava "empacada". Esse episódio ilustra como o espaço de manobra do professor pode ampliar-se por uma negação. No caso, o grupo estava aprendendo que nem sempre é possível lançar uma pergunta para os alunos ocultando qualquer dica para a resposta, ou seja, foi necessário flexibilizar o pacto inicial dos licenciandos.

Marina acatou prontamente a atitude de Gil (turno 27) e conduziu o processo propondo que os alunos desenvolvessem uma investigação, no que foi seguida por Eduardo. Naquele momento, além deles, Kenia, Kátia e Gil encontravam-se na posição central, diante da turma. Vejamos o desfecho do episódio.

\section{Quando a realidade e a imaginação se confrontam}

Laura, uma das alunas, demonstrou desejo de ir ao quadro apresentar sua sugestão e foi incentivada por Kátia, Kenia e Marina a mostrar o que tinha em mente. Laura então aproveitou o desenho que Gil havia produzido e acrescentou uma linha que poderia ser interpretada por qualquer professor de matemática como uma reta tangenciando a circunferência (Figura 5).

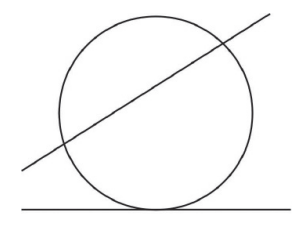

Figura 5

Apesar de parecer ser essa sua tentativa, Eduardo ainda lhe fez uma pergunta: "Como é que você chamaria esse exemplo seu? O que está acontecendo?”.

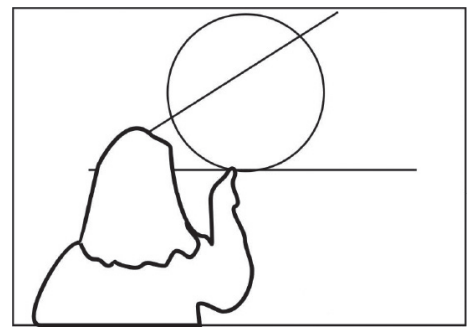

Figura 6

Laura respondeu falando muito baixo, de maneira incompreensível, e passando o indicador no seu desenho pelo espaço em que circunferência e reta se encontravam (Figura 6). Gil, desconsiderando a resposta e percebendo o movimento de uma outra aluna, perguntou se alguém teria dito alguma coisa. Imediatamente, Laura voltou-se de frente para os colegas. A aluna, que se havia levantado, disse que aquilo (o desenho de Laura) seria uma tangente. Marina sugeriu que ela então fizesse o desenho dessa posição que estava sugerindo e esclareceu para a turma que, 
segundo essa aluna, no desenho de Laura a reta ainda encostava a circunferência em dois pontos. Laura tentou explicar-se e foi assistida por Kenia e Marina. O episódio prosseguiu com este diálogo:

\section{Episódio 3}

1. Laura ((Voltando-se para seu desenho)): Como ela (a linha) está grossa...

2. Kenia ((Caminhando em direção a Laura)): Você queria fazer o quê? Faz uma (reta) mais fina... Vamos ver.

3. Marina: Qual é a sua intenção? Primeira coisa.

4. Laura: Não cortar a... ((Laura vai apagando a reta que havia desenhado e, por gestos, imitando uma reta cortando a circunferência, mostra que não pretende fazer uma secante)).

5. Marina: Não cortar em dois pontos?

6. Laura: É.

7. Marina: Vamos ver... ((Laura vai fazendo seu segundo desenho, que é uma reta praticamente na mesma posição daquela do primeiro desenho. Enquanto desenha, é observada bem de perto, à sua esquerda, por Kenia e Gil e, à sua direita, por Marina, que se encontra um pouco mais afastada)).

8. Kenia: Cortar em quantos pontos?

9. Laura: Que não seja em dois pontos. ((Sorrisos)).

10. Kenia: Tem jeito de não cortar em dois pontos?

11.Laura: Não... ((Sussurros)). Só se fosse mais...

12. Marina: Bom, pergunta interessante. Será que a reta pode tocar a circunferência em mais de dois pontos? Três por exemplo? ((Silêncio. Neste momento, Laura volta-se novamente para a turma e se aproxima da professora)).

13. Kenia: O que vocês acham? ((Alunos fazem alguns comentários entre si)).

14. Marina: Uma circunferência e uma reta... A reta pode cortar essa circunferência em mais de dois pontos?

15.A1: Não. ((Fala baixo)).

16. Marina: Vocês acham que não? ((Silêncio; os alunos não respondem)).

17. Eduardo ((Entrando em cena, aproxima-se do quadro e vai apontando para o desenho de Laura enquanto fala)): Só se for igual (ao que) ela fez aqui, ó. Você põe bem no cantinho aqui até que tem um monte de pontos da circunferência que vão encontrando a reta. ((Sorrisos de Kenia e da professora Marina)).

18. Marina: Não é só um, nem dois, nem três... Tem uma porção.

19. Eduardo: É mesmo. Tem uma porção aqui. ((Sorrisos)).

20. Marina: Mas a intenção da Laura aqui era desenhar.. Encostando em quantos pontos, Laura? ((Eduardo vai retirando-se de cena)).

21.Laura: Não... Encostar... Nesse pedacinho... ((Passa o indicador pela região do desenho em que a reta e a circunferência se tocam)).

22.Eduardo: Um monte (de pontos).

23.Laura: É... Um monte... De algum jeito que não fosse em dois pontos ((Vai gesticulando, indicando a secante já desenhada para reforçar a idéia de que queria desenhar uma reta em uma outra posição)).

24. Kenia ((Olhando para Laura e falando para ela)): Mas só que não tem jeito de encostar em muitos pontos. Aqui o desenho não fica exatamente do jeito que a gente quer. ((Vai passando o indicador pela mesma região que Laura indicara anteriormente - a região em que reta e circunferência se encontram)).

25. Kátia: O Ângelo tinha falado sobre precisão, vocês lembram? ((Passa um giz para Kenia, que pretende desenvolver sua explicação com desenhos. Laura volta-se para seu desenho, seguindo a reta que havia desenhado com gestos. Vozes confusas, ela parece estar em dificuldades para explicar melhor sua idéia)).

26. Kenia: Desenha a circunferência bem fininha para ver o que você acha, desenha. ((Laura desenha outra reta bem próxima da que havia desenhado - Figura 7)).

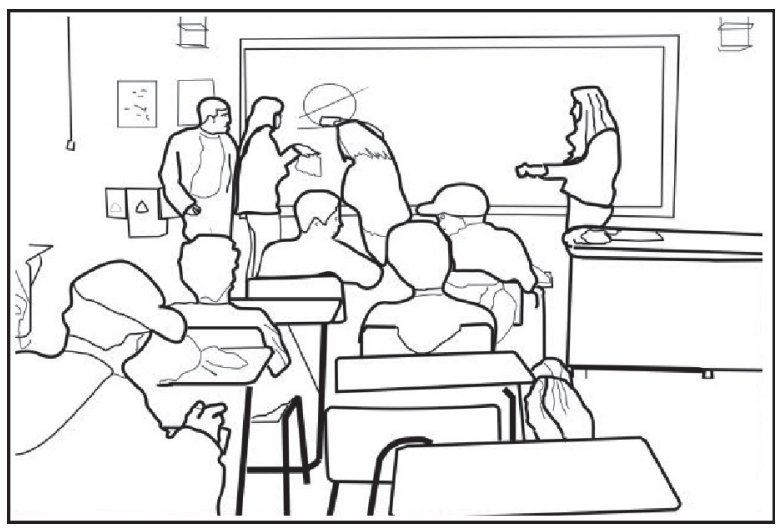

Figura 7 
27. Kenia: Olha, não está encostando. Você queria que não encostasse.

28. Eduardo: Você queria que não encostasse?

29. Kenia ((Dirigindo-se à turma)): Gente, ó, ela fez um desenho mais ou menos assim... Só que ela fez bem pertinho. Certo, ela fez não encostando em nenhum ponto.

30. Eduardo ((Interrompendo Kenia)): Então é uma terceira posição, olha. Vamos ver o que nós descobrimos: tem a reta que encosta em dois pontos, tem a reta que encosta em muitos pontos ((desenha uma outra reta como a de Laura)), a gente nem sabe quantos, e tem uma reta que não encosta... São coisas diferentes. ((Nesta fala, todos os alunos flagrados pela câmera 2 , exceto um - que desenhou o tempo todo da aula -, estão mostrando atenção ao quadro e à fala do professor)). Agora, essa aqui foi a que eu gostei mais ((Apontando para a posição sugerida por Laura)), porque encosta em muitos pontos ((Sorrindo e dirigindo-se aos colegas)). Quero ver como vocês vão sair dessa.

31. Kenia: Por que dá a impressão, gente, de que (a reta) encosta em vários pontos (da circunferência)? ((Laura entrega seu giz à professora Marina e vai retirando-se para sentar-se em sua cadeira)).

32.Eduardo ((Sorrindo)): É porque encosta. Você não está vendo que encosta, não? ((Sorrisos soltos; os alunos flagrados pela câmera 2 também sorriem; tempo... Gil sai de cena, apenas Kenia e a professora permanecem)).

O episódio 3 ocorreu em um clima muito bemhumorado. E foi nesse clima que a intervenção do professor Eduardo marcou uma ruptura na forma de conduzir a aula. Até então, os licenciandos procuravam portar-se da maneira em que se sentiam seguros. Significa que controlavam as perguntas que deveriam fazer para os alunos, de forma que as repostas pudessem colaborar para a condução dos assuntos contidos na programação. Além disso, as dúvidas que surgiam eram repassadas para a turma, para que os próprios alunos as solucionassem sempre que possível, como no caso em que uma aluna perguntou à Kátia de que tamanho ela deveria desenhar a reta.
Para Kenia, diante do desenho proposto por Laura, a atitude correta a ser adotada, e que ela vinha tentando implementar, seria corrigir a proposta da aluna e convencê-la de que, se seu desenho fosse mais preciso, a reta tangenciaria a circunferência (turno 29). Contudo, Eduardo interrompeu esse processo (turno 30) e deu destaque para o que o desenho evidenciava. Kenia ainda tentou retomar o controle da situação (turno 31), mas a resposta que Eduardo forneceu à sua pergunta deixou claro que ele não pretendia deixar espaço para que a idéia oferecida pela aluna fosse corrigida (turno 32). Nesse momento, ele estava seguro do que pretendia, e sua firmeza, associada ao fato de estar ali como um professor mais experiente que os licenciandos, impeliu o grupo de professores a enfrentar uma condição não prevista no planejamento. Estava produzida uma tensão e, com ela, oportunidades para que todos aprendessem. Essas oportunidades, de fato, ocorreram durante a aula e posteriormente, nas avaliações do episódio.

Ao propor uma situação inovadora, Laura lançou mão de sua agency (Sewell, 1992), de sua capacidade de usar criativamente os recursos de que dispunha. Ela própria relatou, durante a avaliação do episódio, que, sentindo-se segura para arriscar uma idéia que lhe ocorrera, se aproveitou da ocasião para propôla aos professores. Além disso, Laura atendeu a seu desejo de fazer algo que contrariasse uma forma de autoridade sempre presente nos processos escolares. Ela conhecia a idéia de tangência, mas queria produzir algo novo - uma "tangente" que cortasse a circunferência em dois ou mais pontos. Segundo suas próprias palavras durante a avaliação do episódio: "Eu sempre penso em contrariar... Contrariar uma idéia que já está aí. Eu sempre tento uma maneira de contrariar, que essa é minha intenção, sempre". Naquele momento, quando decidiu usar sua agency e desafiar o que considerava um conhecimento instituído, Laura tinha em mente suas experiências passadas e as possibilidades do futuro imediato, que poderia prever dadas as condições do ambiente (Emirbayer \& Mische, 1998). A avaliação posterior do episódio permitiu que ela tomasse consciência e fosse capaz 
de expressar em palavras o que experimentou durante a ação. Para ela, o ambiente seria receptivo, uma vez que estava acostumada com a professora (Marina), que permitia que os alunos expressassem livremente suas idéias. Com seu desenho, entretanto, não conseguiu convencer os outros (os colegas e os professores) de que existiria a reta tangente em dois pontos, como imaginara. Diante do impasse e da tensão causada pela pressão daqueles que pretendiam corrigir seu desenho, não soube como argumentar em seu favor. Entretanto, não recuou, ou seja, não admitiu que, no limite, haveria apenas a possibilidade de a reta tocar a circunferência em um ponto. Como explicou mais tarde, para ela, um ponto teria dimensões arbitrárias: “[...] um ponto pode ser dois, porque a gente não sabe o tamanho de um ponto. $\mathrm{E}$ eu não tinha isso claro".

Eduardo, por seu lado, não conhecia as intenções de Laura, mas percebeu que ela pretendia produzir algo inovador e que resistia à idéia de simplesmente acatar o que Kenia estava tentando lhe ensinar. Usou então de sua agency para impedir que a idéia fosse, de certa forma, deturpada e suplantada pelo que seria considerado correto pela matemática escolar convencional. Tal ação colocou uma possibilidade diferente ainda não considerada pelos licenciandos.

Os licenciandos ficaram perplexos diante do desafio que fora lançado. Ângelo disse que: "Primeiro a gente riu, depois que a gente viu que os alunos estavam apoiando essa idéia, a gente viu que a coisa estava complicada". Kenia comentou: "Eu achei que ele (Eduardo) estava brincando. Depois: o quê? Como assim? Tem certeza?". Kátia, por seu lado, afirmou: "Eu sei que, nessa hora, eu sumi". De fato, os licenciandos, exceto Kenia, retiraram-se para o fundo da sala. Kenia expôs assim sua percepção do momento: "Na hora, eu pensei em sair também. Sabe qual foi a sensação que eu tive? Foi ele quem arrumou a confusão, agora, ele que resolva. Porque está todo mundo se ajudando aqui, forçando os meninos a ir por um caminho... Ele vai e ajuda a desviar mais ainda... Agora, ele que assuma”.

\section{Mudanças de rumo e de perspectiva de aprendizagem}

Iniciamos este artigo apostando na possibilidade de que a criação de um ambiente em que professores veteranos compartilhem a aula com iniciantes permita um confronto direto com pressupostos de todos os participantes, possibilitando a construção de um conhecimento que só se realiza na prática. Comentamos, ainda, a dificuldade de perceber a aprendizagem do grupo quando este se encontra em movimento. Uma possibilidade seria pensar na aprendizagem enquanto participação dos sujeitos envolvidos em atividades concretas (Goulart, 2005). Isso posto, cabe-nos examinar de que forma os professores veteranos e os iniciantes criaram um clima propício para avançar a compreensão de todos sobre o que acontecia naquele momento. Da parte dos licenciandos, as concepções sobre o ensinar e $\mathrm{o}$ aprender estavam problematizadas. Da parte dos alunos, para além do conceito de tangente, um novo conhecimento estava por eclodir.

Quando os licenciandos presenciaram os primeiros movimentos de Eduardo, talvez por sua postura relaxada e sorridente, pensaram que ele estava simplesmente ironizando e que iria, em seguida, tomar o caminho que o grupo considerava correto. Ao perceberem que ele estava determinado a valorizar o que sugeria o desenho de Laura, viram-se diante de uma situação tão desconhecida que pensaram que não haveria saída além de provocar uma confusão indesejável na mente dos alunos. Isso decorria de sua percepção de que as afirmações dos alunos deveriam ser consideradas apenas no que elas poderiam contribuir para o desenvolvimento de conteúdos previamente estabelecidos. No entanto, Eduardo assumia estar diante de uma novidade e confiava na possibilidade de investigar a fundo o que a aluna estava apresentando.

$\mathrm{Na}$ avaliação do episódio, Eduardo contou para o grupo de professores o que tinha em mente, embora tenha agido quase sem tempo para pensar, movido por uma percepção forjada pela experiência de lecionar, ou seja, movido por um habitus adquirido. Na verdade, 
ele nunca havia passado pela mesma situação em uma sala de aula e, portanto, sua ação constituiu, também, uma aposta na possibilidade de obter oportunidades ricas em aprendizagens, mesmo que essas oportunidades ainda não estivessem claramente delineadas. Seu primeiro motivo foi forçar o grupo a acatar a idéia de Laura com mais precisão. A atitude da aluna sugeria que ela estava presa ao desenho, ou seja, ao dado empírico. E não é possível desenhar uma tangente, apenas imaginá-la. Eduardo intuiu que o desenho de Laura punha a descoberto o fato de haver uma distância entre aquilo que os alunos podiam perceber empiricamente e o que se estava demandando que eles compreendessem. Para entender a idéia de tangente é preciso conceber uma situação imaginária, com uma reta e uma circunferência infinitamente finas. Euclides, por exemplo, no livro I de sua obra Os elementos, define a reta como uma linha sem largura, ou seja, algo que não é possível desenhar. ${ }^{4}$ Com sua atitude, Laura abria a possibilidade de colocar em pauta uma contraposição entre a realidade empírica e a imaginação que está presente na teorização. Uma situação como essa assemelha-se a processos de produção de conhecimento que teriam acontecido em momentos determinados da história. Koyré, filósofo francês, confirma:

As experiências imaginárias [...] desempenharam um papel muito importante na história do pensamento científico. Isso se compreende facilmente: as experiências reais são, freqüentemente, de difícil realização, pois implicam, não menos freqüientemente, a necessidade de uma complexa e custosa aparelhagem. Além disso, comportam, necessariamente, certo grau de imprecisão e, portanto, de incerteza. Com efeito, é impossível produzir uma superfície plana que seja "verdadeiramente" plana, ou uma superfície esférica que seja “realmente" esférica. Não há, e não pode haver, in rerum natura, corpos perfeitamente rígidos; tampouco, corpos

${ }^{4}$ A definição II do livro I de Os elementos é a seguinte: "Linha é o que tem comprimento sem largura". A obra pode ser acessada em: http://www.direitoprocessual.com.br/textos/Euclides. htm. perfeitamente elásticos. Não se pode efetuar uma medida perfeitamente exata. A perfeição não pertence a este mundo. Certamente, pode-se aproximar dela, mas não se pode atingila. Entre o dado empírico e o objeto teórico existe, e sempre existirá, uma distância que é impossível vencer.

É aí que a imaginação entra em cena, eliminando facilmente o abismo. Ela não se embaraça nas limitações que nos são impostas pelo real. Ela "realiza" o ideal e até o impossível. Opera com objetos teoricamente perfeitos, e são tais objetos que a experiência imaginária põe em jogo. (1982, p. 209)

Koyré escreve para filósofos ou para cientistas. Não imagina, portanto, a dificuldade que os adolescentes enfrentam para compreender como os matemáticos trabalham com a imaginação. Essa dificuldade estava evidenciando-se no episódio relatado. Todavia, por ter determinado uma mudança de rota, Eduardo teve de enfrentar alguns desafios: decidir rapidamente o que fazer e não tomar muito tempo da aula, porque os licenciandos tinham uma programação a ser cumprida. Resolveu, então, dizer para os alunos que aquilo que o desenho da colega sugeria era aceitável: ali, muitos pontos eram comuns à reta e à circunferência. Explicou, ainda, que, enquanto os alunos estavam trabalhando com a realidade (empírica), os professores estavam usando a imaginação própria dos matemáticos. Depois de falar, retirou-se de cena.

Ângelo, do local onde se encontrava, também sugeriu que os alunos pensassem em uma esfera em contato com o chão e perguntou em quantos pontos ela o tocaria. Essa sugestão de Ângelo expressa um momento em que, depois de passada a perplexidade e depois de um tempo em que pôde refletir sobre o que estava ocorrendo, ele se sentiu novamente confortável para retomar a participação no debate. Eduardo voltou a assumir a posição central para falar para os alunos que qualquer exemplo extraído do mundo empírico esbarraria na mesma dificuldade, ou seja, sempre haveria muitos pontos comuns a uma bola e o chão, um pneu de automóvel e o chão e até mesmo uma roda de aço de uma locomotiva e o trilho.

Enquanto reviam o episódio, Kátia comentou que o debate teria sido bastante significativo para os pro- 
fessores, mas provavelmente pouco teria atingido os alunos. Cabia, então, pedir que eles relatassem como perceberam os eventos, o que foi feito na reunião de avaliação de que participaram.

\section{Lições que os alunos aprenderam e ensinaram}

Além dos professores, exceto Gil, oito alunos participaram da avaliação do episódio, conforme a disponibilidade de horário. Os alunos assistiram às cenas iniciais da aula e puderam familiarizar-se com sua condição de expectadores e avaliadores antes de assistir ao episódio que interessava mais especificamente. Quando reviram o momento em que Laura fez o desenho no quadro, foi perguntado a Laura qual teria sido sua intenção. Ela esclareceu, então, que estava tentando desenhar uma "tangente" que se encostasse à circunferência em dois pontos. Sua argumentação baseava-se na idéia de que um ponto, porque teoricamente não tem dimensões, poderia ter várias: poderia ser dois, três ou mais pontos ao mesmo tempo, dependendo da decisão arbitrária de cada pessoa. Ela terminou por confessar que não tinha uma idéia clara do significado da definição de ponto.

Laura afirmou que tinha consciência do que era a expectativa dos professores, ou seja, do que seria a resposta que eles esperavam, uma vez que já conhecia a definição teórica de tangente.

Essa aluna deixou-nos ainda um recado bastante precioso. Comentando a expectativa dos professores de que os alunos dissessem que havia apenas três posições relativas entre a reta e a circunferência, ela afirmou: "Não é simples o fato de que a tangente encosta (na circunferência) em um ponto só. Simples é a gente falar isso". Nesse momento, ela estava afirmando que, do seu ponto de vista, repetir conceitos com as mesmas palavras do professor é uma tarefa mental simples. Contudo, é difícil compreender profundamente o significado da teoria. Enquanto leciona, é fácil um professor deixar-se cair nessa armadilha. Se os alunos sabem formular de memória os conceitos que o professor está ensinando, a tendência mais comum é avaliar a fala dos alunos como aquisição de conhe- cimento. O depoimento de Laura, portanto, colocou em xeque a idéia dos licenciandos, de que fariam os alunos construir conhecimentos por meio de um diálogo conduzido. Laura mostrou que os alunos podem perfeitamente descobrir respostas que os professores estão na expectativa de ouvir sem, contudo, construir realmente o conceito colocado na pauta.

Como Laura tomou consciência disso? Do nosso ponto de vista, não foi somente pela reflexão, mas pela ação e reflexão. Propondo sua idéia, enfrentando questionamentos, desenhando, observando seu desenho, refletindo, explicando-se, foi evoluindo no seu ponto de vista. A tomada de consciência deu-se, então, nesse embate, nessas tensões inerentes à atividade. Mas o processo de Laura deu-se de maneira integrada à evolução dos demais participantes ou, dito de outra maneira, a construção de conhecimento aconteceu no contexto de um movimento coletivo no qual todos se apropriaram de novos saberes. Para os professores, a revelação de que Laura tinha domínio da definição de tangente foi uma surpresa. Até o encontro com os alunos para a avaliação do episódio, havia percepção de que Laura se ateve ao desenho que havia feito. Os professores não tinham idéia de que ela tentava questionar uma definição que conhecia, mas que não compreendia em profundidade.

E os licenciandos, como ampliaram sua visão de aprendizagem dos alunos? A mudança na direção da aula provocada pelo professor veterano foi crucial. Agindo, ele problematizou a idéia inicial dos licenciandos, na qual a construção de conceitos se faz tendo por base um diálogo conduzido. No nosso exemplo, a revelação de que a aluna já sabia a resposta correta confirmou o engano inerente ao pacto estabelecido por eles desde o planejamento das aulas.

A intervenção do professor veterano mostrou que era possível ir além da apropriação do conceito matemático clássico e explorar caminhos desconhecidos. $\mathrm{O}$ fato de ter acolhido e enfrentado o desafio proposto pela aluna provocou autêntica investigação de um conhecimento novo que estava emergindo. Aquele de que, entre a realidade concreta da vida e a teoria construída pelos cientistas, existe uma distância 
impossível de vencer. Daí o papel da imaginação. Daí a fecundidade de uma verdadeira investigação em sala de aula.

\section{Conclusão: a atividade integrada à formação profissional}

A atividade aqui relatada poderia ser considerada em uma perspectiva que restringiria os acontecimentos a uma proposta de compartilhamento de aulas entre professores veteranos e iniciantes seguido de análises críticas de dois grupos diferenciados: o dos professores e o dos professores e alunos. Dessa perspectiva, poderíamos destacar alguns movimentos significativos. Os licenciandos entraram no processo com uma percepção da prática docente que se foi ampliando a partir de um questionamento da proposta que estavam encaminhando. A princípio, quando foi alterado o padrão de relacionamento com o conhecimento escolar, os licenciandos consideraram que não haveria continuidade razoável do encaminhamento da aula e que os alunos ficariam confusos em razão de uma valorização de um pensamento em desacordo com os cânones da matemática escolar. Não tinham, portanto, incorporado em seu leque de opções a possibilidade de seguir, e até reforçar, o raciocínio de um aluno contrário às crenças do professor. Contudo, a análise dos acontecimentos permitiu que se constatasse que a assunção da proposta "errada" frutificou em novos conhecimentos acerca de como os alunos interpretam determinadas definições teóricas e da luta que empreendem na tentativa de ajustar suas próprias crenças àquilo que devem admitir como a forma correta de interpretar a realidade.

Portanto, a atividade oportunizou, para os licenciandos, um alargamento do seu espaço de manobra. $\mathrm{O}$ compartilhamento de aulas permitiu que os professores veteranos explorassem possibilidades de atuação até então desconhecidas. Reconhecemos, contudo, que essa experiência foi um ponto de partida na formação dos iniciantes. A condução de uma aula mais dialogada, na qual as idéias dos alunos não servem apenas para reforçar o que o professor quer ensinar, dependerá ainda de muito tempo de exposições a situações se- melhantes ou do fortalecimento do habitus necessário para que isso seja feito com naturalidade.

Além disso, mesmo apostando no diálogo com as idéias dos alunos, os professores veteranos somente tiveram uma dimensão mais profunda do que ocorreu nas discussões posteriores às aulas. Na nossa perspectiva, o depoimento dos alunos enriqueceu os conhecimentos de todos, inclusive porque demonstrou que é preciso muito tempo e trabalho intelectual para compreender determinadas idéias há muito estabelecidas na matemática formal, que podem parecer simples para os adultos familiarizados com o assunto - que tendem a esquecer o esforço que empreenderam enquanto estudavam.

Os alunos puderam experimentar livremente suas idéias e enfrentar o debate crítico sobre o que estava sendo proposto. Puderam trocar de perspectiva. Em vez de a situação ser avaliada do ponto de vista do senso comum, ou seja, da dificuldade dos alunos em aprender determinados conteúdos matemáticos, os alunos foram vistos como aqueles que ampliaram possibilidades de aprendizagem para todo o grupo, colocando à mostra o trabalho intelectual necessário para a construção de conceitos tão abstratos.

Quando ampliamos a perspectiva de análise, constatamos que são inumeráveis os fatores que contribuíram para que os indivíduos tomassem determinadas decisões e fizessem determinadas escolhas. Os acontecimentos passados e as condições do grupo de origem de cada ator e sua localização na sociedade são componentes desses fatores. Contudo, podemos considerar, como Sewell (1992), que a sociedade se organiza em estruturas de diversos níveis. Ao mesmo tempo em que as possibilidades de ação dos sujeitos são constrangidas por essas estruturas, a ativação da agency possibilita a operação de mudanças. A atividade humana não só reproduz as condições vigentes como também opera transformações no interior das estruturas.

O compartilhamento de aulas e a análise dos episódios pelos envolvidos geraram formas originais de agir e de pensar absorvidas e ressignificadas pelos atores. Assim, alunos e professores produziram novas 
possibilidades de ação que poderão ser retomadas nas estruturas sociais por onde transitam. Essa perspectiva, que destaca como as ações humanas inevitavelmente se conectam, coloca-nos em contato com os grupos humanos em larga escala. Isso nos estimula a considerar que a reflexão e o registro dos eventos, também produtos da atividade empreendida, poderão contribuir para o avanço das reflexões de educadores em outros contextos.

\section{Referências bibliográficas}

BOURDIEU, Pierre. Esboço de uma teoria da prática. In: ORTIZ, R. (Org). Pierre Bourdieu. São Paulo: Ática, 1983.

EMIRBAYER, Mustafa; MISCHE, Ann. What is agency? The American Journal of Sociology, v. 103, n. 4, p. 962-1023, jan. 1998.

FIORENTINI, Dario; NACARATO, Adair Mendes; PINTO, Renata Anastácio. Saberes da experiência docente em matemática e educação continuada. Revista Quadrante, v. 8, n. 1 e 2, p. 33-59, jan./fev. 1999.

GALLO-FOX, Jennifer; WASSELL, Beth; SCANTLEBURY, Kathryn; JUCK, Matthew. Warts and all: ethical dilemmas in implementing the coteaching model. Forum Qualitative Social Research, v. 7, n. 4, art. 18, sept. 2006.

GOULART, Maria Inês Mafra. A exploração do mundo físico pela criança: participação e aprendizagem. Tese (Doutorado em Educação) - Faculdade de Educação, Universidade Federal de Minas Gerais, Minas Gerais, 2005.

KOYRÉ, Alexandre. Estudos de história do pensamento científico.

Trad. Márcio Ramalho. Rio de Janeiro: Forense-Universitária, 1982.

PRIGOGINE, Ilya. O fim das certezas: tempo, caos e as leis da natureza. Trad. Roberto Leal Ferreira. São Paulo: Editora da UNESP, 1996.

ROTH, Wolff-Michael. Authentic School Science: knowing and learning in open-inquiry science laboratories. Netherlands: Kluwer Academic, 1995.

. Being and becoming in the classroom. Connecticut/ London: Alex Publishing Westport, 2002.

Ethical issues when teaching praxis is coextensive with qualitative research praxis. Forum Qualitative Social Rese-

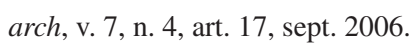

; TOBIN, Kenneth. At the Elbow of Another. New

York: Peter Lang Publishing, 2002a.

. Redesigning an "urban" teacher education program: an activity theory perspective. Mind, Culture and Activity, v. 9, n. 2, p. 108-131, apr./jun. 2002b.

Cogenerative dialoguing and metaloguing: reflexivity of processes and genres. Forum Qualitative Social Research, v. 5, n. 3 , art. 7, sept. 2004 .

.; ELMESKY, Rowhea; CARAMBO, Cristobal; MCKNIGHT, Ya-Meer; BEERS, Jen. Re/Making identities in the praxis of urban schooling: a cultural historical perspective. Mind, Culture and Activity, v. 11, n. 1, p. 48-69, jan./mar. 2004.

SEWELL, William H. Jr. A theory of structure, agency and transformation. American Journal of Sociology, v. 98, I. 1, p. 1-29, jul. 1992.

SOARES, Eduardo Sarquis. Talking about challenges of being a teacher. Forum: Qualitative Social Research, v. 5, n. 3, art. 5, sept. 2004.

TARDIF, Maurice. Saberes docentes e formação profissional. Petrópolis: Vozes, 2002.

TOBIN, Kenneth; ROTH, Wolff-Michael; ZIMMERMANN, Andrea. Learning to teach science in urban schools. Journal of Research in Science Teaching, v. 38, n. 8, p. 941-964, oct. 2001.

EDUARDO SARQUIS SOARES, doutorando em educação pela Faculdade de Educação da Universidade Federal de Minas Gerais (UFMG), é professor do Departamento de Ciências e Matemática do Centro Universitário da Fundação Educacional Monsenhor Messias, pesquisador do grupo de estudos e pesquisas em "Teoria da Atividade e Educação Matemática” da UFMG. Publicações recentes: "Talking about challenges of being a teacher - review essay: Wolff-Michael Roth Being and Becoming in the classroom (2002)" (Forum Qualitative Sozialforschung, v. 5, n. 3, art. 5, sept. 2004); "Social reproduction and transformation in math teaching" (In: INTERNATIONAL CONFERENCE IN MATHEMATICS, SCIENCES AND SCIENCE EDUCATION, Aveiro, 2006. Anais..: Aveiro: Universidade de Aveiro, 2006. p. 152-161); e "Saberes docentes e transformação social: análise de um compartilhamento da condição de professor" (In: ENCONTRO BRASILEIRO DE ESTUDANTES DE PÓS-GRADUAÇÃO EM EDUCAÇÃO MATEMÁTICA, 10., Belo Horizonte, 2006. Anais... Belo Horizonte: Faculdade de Educação, 2006. 1 CD-ROM). Pesquisa em andamento: "Professor/professora, sujeitos em formação", sob a 
orientação da professora doutora Maria Manuela Martins Soares David.E-mail: esarquis@gmail.com

MARIA INÊS MAFRA GOULART, doutora em educação pela Universidade Federal de Minas Gerais (UFMG), é professora da Faculdade de Educação da mesma instituição, na qual também é pesquisadora do Grupo de Estudos sobre a Condição Docente (PRODOC) e do Grupo de Estudos e Pesquisas em Teoria da Atividade e Educação Matemática. Publicações recentes: em co-autoria com ROTH, Wolff-Michael; HWANG, SungWon; LEE, Yew Jin. Participation, learning and identity: dialectical perspectives (Berlin: Lehmanns Media, 2005); "Margin/Center: toward a dialectical view of participation", em co-autoria com ROTH, Wolff-Michael (Journal of Curriculum Studies, v. 38, n. 6, p. 679-700, nov./dez. 2006); "Querubins ou rebeldes? Um conto de fadas às avessas", em co-autoria com SOARES, Eduardo Sarquis (In: TEIXEIRA, Inês; LARROSA, Jorge; LOPES, José Miguel (Orgs.). A infância vai ao cinema. São Paulo: Autêntica, 2006. p. 179-192). Pesquisa em andamento: "Infância e conhecimento: investigando práticas de escolarização na educação infantill”. E-mail: marinesmg@ gmail.com

Recebido em abril de 2007 Aprovado em janeiro de 2008 
Eduardo Sarquis Soares e Maria Inês Mafra Goulart

Aulas compartilhadas na formação de licenciandos em matemática

Este artigo descreve e analisa uma 
experiência inserida no processo de formação de alunos de licenciatura. São sujeitos da pesquisa quatro licenciandos de matemática da Universidade Federal de Minas Gerais (UFMG), o professor de prática de ensino de matemática da mesma universidade, a professora e os alunos de uma turma da sétima série do ensino fundamental. Os licenciandos planejaram duas aulas de geometria e compartilharam a posição de professor com os demais professores. O compartilhamento das aulas seguiu uma proposta teóricometodológica, coteaching, difundida na literatura acadêmica. As aulas foram filmadas e um episódio foi selecionado para análises posteriores. Em três sessões separadas, as análises incluíram todos os sujeitos participantes. Os resultados obtidos destacam a importância de aprendizagens que só ocorrem na atuação prática e sugere a utilização da metodologia de maneira mais ampla na formação de professores.

Palavras-chave: formação de professores; coteaching; práxis; ensino de matemática

\section{Shared classes in the training of future mathematics teachers}

This article describes and analyses an experience which was part of a student teacher training course involving four mathematics students from the Federal University of Minas Gerais (UFMG), the lecturer of the practice of teaching in mathematics and a teacher and students from the seventh grade of elementary education. The student teachers planned two geometry classes and shared their position as teachers with other teachers. The practice of shared classes follows a theoretical methodological approach known in the academic literature as "co-teaching". The classes were videotaped and one episode was selected for detailed analysis. Analysis took place in three sessions, with the participation of all the students and teachers. The results show the importance of learning from practice and suggest that co-teaching is a fertile way to improve teachers' practice.

Key words: teacher training; coteaching; praxis; mathematics teaching

Clases compartidas en la formación de licenciados en matemáticas

Este artículo describe y analiza una experiencia incluida en el proceso de formación de alumnos de licenciatura. Son sujetos de la pesquisa cuatro licenciados de matemáticas de la Universidade Federal de Minas Gerais (UFMG), el profesor de práctica de enseñanza de matemáticas de la misma universidad, la profesora y los alumnos de una clase del octavo año de la enseñanza primaria. Los licenciados planearon dos clases de geometría y compartieron la posición de profesor con los demás profesores. Después de compartir las clases siguió una propuesta teórica metodológica, coteaching, difundida en la literatura académica. Las clases fueron filmadas y un episodio fue seleccionado para análisis posteriores. En tres sesiones separadas, los análisis incluyeron todos los sujetos participantes. Los resultados obtenidos destacan la importancia de aprendizajes que sólo ocurren en la actuación práctica y sugiere la utilización de la metodología de manera más amplia en la formación de profesores.

Palabras clave: formación de profesores; coteaching; praxis; enseñanza de matemáticas 